(or non-exclusive for government employees) on a worldwide basis to the BMJ Publishing Group Ltd and its licensees to permit this article (if accepted) to be published in British Journal of Ophthalmology and any other BMJPGL products to exploit all subsidiary rights, as set out in our licence (http:// group.bmj.com/products/journals/instructions-forauthors/licence-forms).

Eye (2011) 25, 959-961; doi:10.1038/eye.2011.57; published online 18 March 2011

\section{Sir, \\ Corneal endothelial toxicity secondary to Asclepias fruticosa}

A single layer of endothelial cells covers the posterior surface of Descemet's membrane of the cornea. Corneal hydration and consequently transparency is primarily a function of the sodium-potassium adenosine triphosphatase $\left(\mathrm{Na}^{+} / \mathrm{K}^{+}\right.$-ATPase $)$pump, expressed in the basolateral membrane of corneal endothelial cells. If this pump is impaired, corneal oedema results. ${ }^{1}$

Cardenolides, also known as cardiac glycosides, are a group of $\mathrm{C}_{23}$ steroids produced in nature by several plant families. These natural toxins protect plants and insects from predation. In humans, they have a cardiotonic activity, which is the basis for much of their pharmacological uses. A receptor for cardenolides is the integral membrane protein $\mathrm{Na}^{+} / \mathrm{K}^{+}$-ATPase. Cardenolides bind the enzyme region of this protein at the endothelial cell surface and inhibit the pump's activity. ${ }^{2}$

Asclepias fruticosa is a small perennial shrub about $1-1.5 \mathrm{~m}$ in height, containing a milky latex with cardiac glycosides and proteolytic activity (Figure 1). ${ }^{3}$ Plants of the genus Asclepias (milkweed family) are widely distributed, mainly in the tropics and subtropics, and are well known causes of death in sheep and cattle in open-range grazing. ${ }^{4,5}$ It is common in grassland and is often planted in gardens because it attracts butterflies.

There has been one previous case report describing painless blurring of vision and corneal oedema following contact with the milky latex of $A$. curassavica. ${ }^{1}$ Herein, we describe the self-limited effects of $A$. fruticosa latex components on the cornea. We also discuss the mechanism of endothelial cell toxicity and provide an update on the current literature on the regulation of the $\mathrm{Na}^{+} / \mathrm{K}^{+}$-ATPase activity and pump function in corneal endothelial cells.

\section{Case report}

A previously healthy 73-year-old farmer presented to our clinic complaining of redness and blurred vision in both eyes (right worse than left). The previous day, he handled the milky latex of an Asclepias shrub and then rubbed his eyes. He did not have any ocular discomfort. On examination, best-corrected visual acuity was counting fingers on the right and 20/40 on the left. Slit-lamp microscopy showed conjunctival hyperemia, stromal

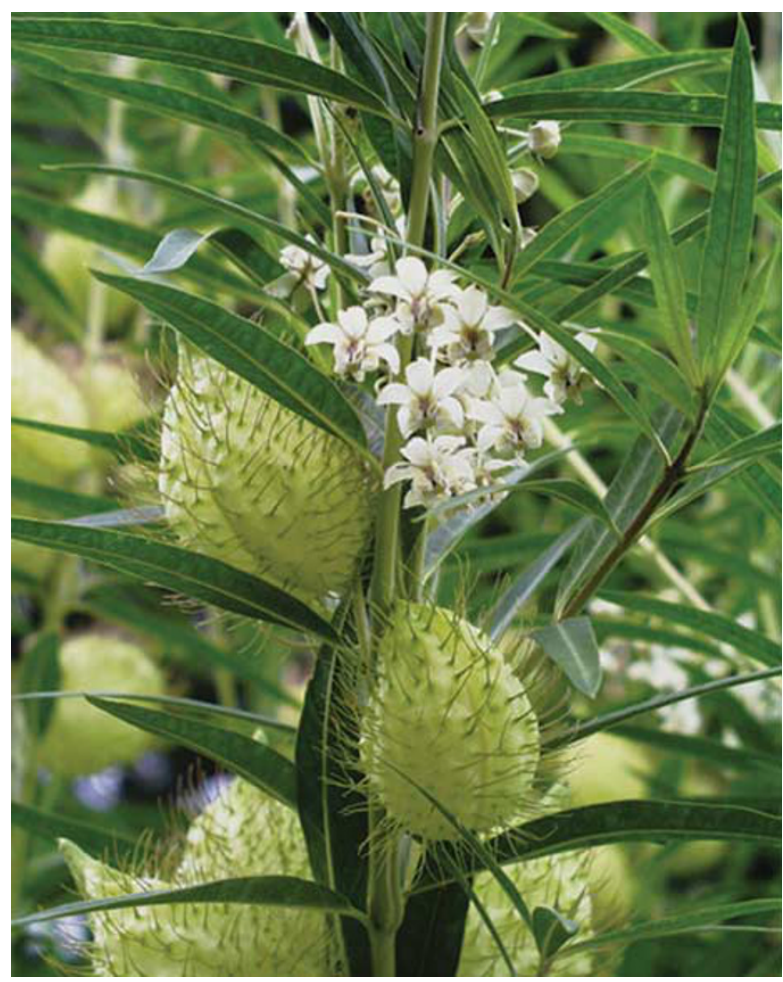

Figure 1 Asclepias fruticosa (copyright permission given by Karlheinz Knoch at the Botanical Garden of Karlsruhe).

corneal oedema with Descemet's folds greater on the right, and a moderate cataract in both eyes (Figures $2 \mathrm{a}$ and $\mathrm{b}$ ). The corneal epithelium was intact. Anterior chamber was quiet with no appreciable flare. Intraocular pressure and posterior segment examination were within normal limits. Both eyes were flushed with saline. Topical dexamethasone $0.1 \%$ eye drops and artificial tears (four times a day) were prescribed. At 3 days after exposure, symptoms and clinical signs showed marked improvement. At 2 weeks after presentation, corneal oedema resolved with a best-corrected vision of $20 / 40$ on the right and 20/30 on the left, consistent with moderate nuclear sclerotic changes. At 9 months after presentation, the patient's corneas remained clear with stable vision (Figure 3).

\section{Discussion}

The plants of the Asclepiadaceae family are known to contain toxic cardiac glycosides in their latex, stems, leaves, and roots. Cardiac glycosides function clinically by inhibiting the enzyme $\mathrm{Na}^{+} / \mathrm{K}^{+}$-ATPase. ${ }^{6}$ Normal functioning of corneal endothelial $\mathrm{Na}^{+} / \mathrm{K}^{+}$-ATPase pump is needed to maintain corneal transparency. ${ }^{7}$ Cardenolides are capable of penetrating the human cornea without major injury to the epithelium. ${ }^{1}$ Topical administration of digitoxin has been shown to cause corneal oedema by inhibiting endothelial $\mathrm{Na}^{+} / \mathrm{K}^{+}$-ATPase. ${ }^{8}$ Similar ocular changes were noted in a patient with systemic digoxin toxicity. ${ }^{9}$

Isolated corneal oedema developed in our patient several hours after the ocular surface had come into contact with traces of the milky latex of an Asclepias 

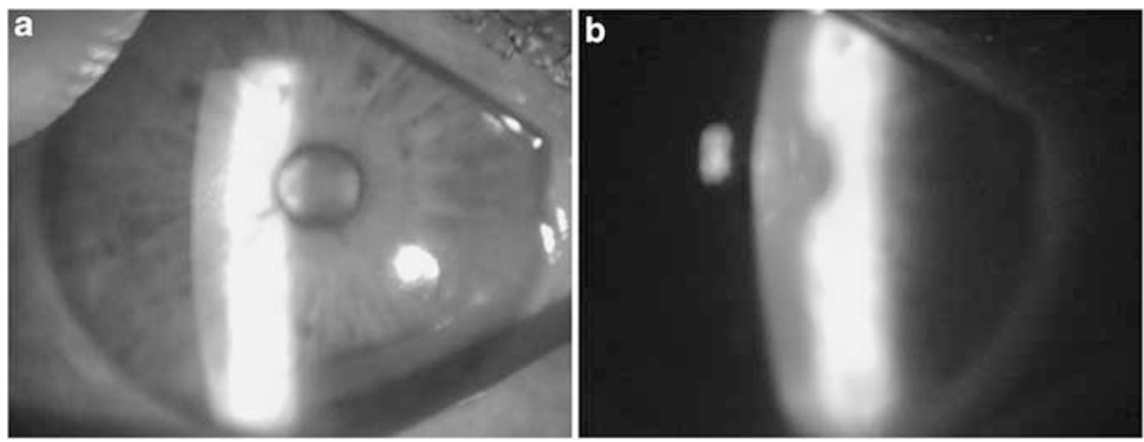

Figure 2 (a and b). Anterior segment photograph of the patient's right eye 1 day after contact with traces of latex from Asclepias fruticosa. Descemet's membrane folds are seen on slit-lamp biomicroscopy.

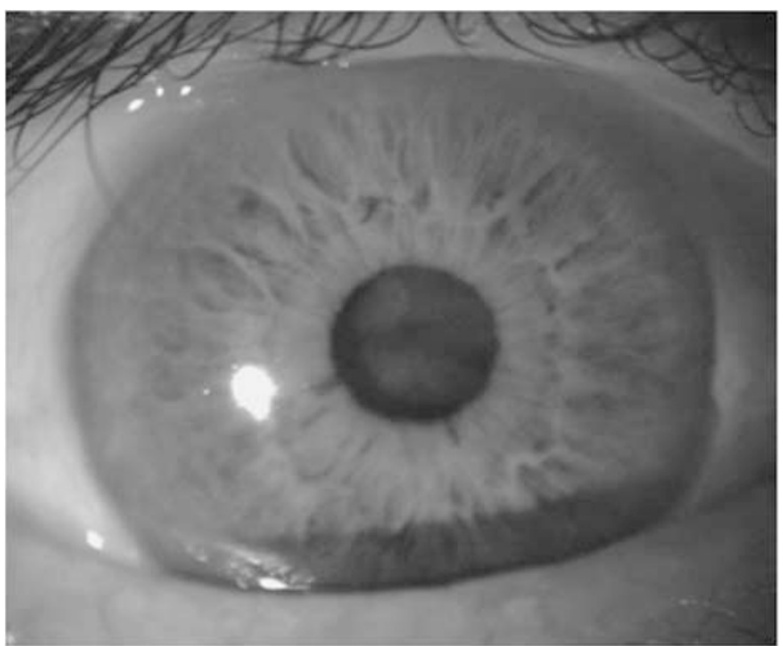

Figure 3 Anterior segment photograph of the patient's right eye 9 months after resolution of corneal oedema following exposure to the milky latex of Asclepias fruticosa.

shrub. The delay in visual blurring is seen with the appearance of digitalis keratopathy after topical administration of digitoxin drops. ${ }^{6}$ There was no epithelial defect. Therefore, these glycosides seem able to penetrate the intact epithelium and to be toxic mainly to the corneal endothelium by inhibiting the endothelial $\mathrm{Na}^{+} / \mathrm{K}^{+}$-ATPase.

Steroidal treatment is often administered to reduce ocular inflammatory symptoms. Recently, a study demonstrated that dexamethasone results in increases in $\mathrm{Na}^{+} / \mathrm{K}^{+}$-ATPase pump activity in cultured corneal endothelial cells. ${ }^{10}$ The use of topical steroids may result in an increase of the pump activity in the remaining receptors that have not been blocked by the cardenolides. This may serve to compensate for some of the lost activity caused by the inhibitory action of the cardenolides and help in the recovery process. Corneal oedema may also disappear spontaneously when inhibition by the cardenolide has ceased. The harm caused by the cardenolides appears to be a temporary dysfunction of corneal endothelial cells that have been exposed to the toxic agent. A previous case involving
A. curassavica reported an effect lasting $24-48$ hours, ${ }^{1}$ whereas our case (A. fruticosa) was resolved by day 3 with supportive treatment. As such, these conditions are typically self-limiting over a few days and associated with a full recovery without sequelae.

Toxic exposures to the cornea are not uncommon. As Asclepias plants are widely distributed, patients presenting with corneal oedema should be asked about possible exposures to plant sap. Knowledge of these toxic plants and their sap constituents may aid in the diagnosis and appropriate management of such cases.

\section{Conflict of interest}

The authors declare no conflict of interest.

\section{References}

1 Chakraborty S, Siegenthaler J, Buchi ER. Corneal edema due to Asclepias curassavica. Arch Ophthalmol 1995; 113: 974-975.

2 Abbott AJ, Holoubek CG, Martin RA. Inhibition of $\mathrm{Na}+\mathrm{K}+$-ATPase by the cardenolide 6'-O-(E-4hydroxycinnamoyl) desglucouzarin. Biochem Biophys Res Commun 1998; 251: 256-259.

3 Trejo SA, Lopez LM, Cimino CV, Caffini NO, Natalucci CL. Purification and characterization of a new plant endopeptidase isolated from latex of Asclepias fruticosa L. Asclepiadaceae). J Protein Chem 2001; 20: 469-477.

4 Joubert J. Cardiac glycosides. In: Cheeke P, editor. Toxicants of Plant Origin. CRC Press: Boca Raton, Florida, 1989; 61-96.

5 Benson JM, Seiber JN, Bagley CV, Keeler RF, Johnson AE, Young S. Effects on sheep of the milkweeds Asclepias eriocarpa and A. labriformis and of cardiac glycosidecontaining derivative material. Toxicon 1979; 17: 155-165.

6 Smith JL, Mickatavage RC. The ocular effects of topical digitalis. Am J Ophthalmol 1963; 56: 889-894.

7 Woodford S, Vanemter WS, Lee WB. Corneal edema. In: Tasman W, Jaeger EA (eds). Duane's Ophthalmology. Lippincott Williams \& Wilkins: Philadelphia, 2006.

8 Hiett J. Inhibitors of aqueous formation. In: Bartlett J, editor. Ocular Pharmacology. Butterworth: Stoneham, 1989; 245-266.

9 Madreperla SA, Johnson M, O'Brien TP. Corneal endothelial dysfunction in digoxin toxicity. Am J Ophthalmol 1992; 113: 211-212.

10 Hatou S, Yamada M, Mochizuki H, Shiraishi A, Joko T, Nishida T. The effects of dexamethasone on the $\mathrm{Na}$, K-ATPase activity and pump function of corneal endothelial cells. Curr Eye Res 2009; 34: 347-354. 
MD Amiran', Y Lang ${ }^{1}$ and SN Yeung ${ }^{2}$

${ }^{1}$ Department of Ophthalmology, Ha'emek Medical Center, Afula, Israel \& The Ruth and Bruce Rappaport Faculty of Medicine, Technion - Israel Institute of Technology, Haifa, Israel

${ }^{2}$ Department of Ophthalmology and Visual Sciences Eye Care Centre, Vancouver Hospital, University of British Columbia, Vancouver, British Columbia, Canada

E-mail: karen_charrach@hotmail.com

Eye (2011) 25, 961-963; doi:10.1038/eye.2011.59; published online 18 March 2011

Sir,

Uveal Effusion Syndrome as a complication of cyclodiode therapy in nanophthalmos glaucoma

\section{Case description}

A 46-year-old woman with nanophthalmos (Table 1) presented with progressive angle closure, pain, and raised intraocular pressure (IOP) in her left eye. She was intolerant of topical antihypertensive agents. She had small, tilted optic discs, and repeated automated Humphrey visual field testing confirmed a left nasal step visual field defect. Bilateral Nd:YAG peripheral iridotomies were performed, which resulted in deepening of the anterior chambers, however, the left IOP continued to remain elevated $(25-30 \mathrm{~mm} \mathrm{Hg})$.

In view of the risks of uveal effusion and aqueous misdirection syndrome following intraocular procedures in nanophthalmic eyes, ${ }^{1}$ trans-scleral diode laser cycloablation was carried out on the left eye. In all, 24 burns of $2000 \mathrm{~mW}$ and $2000 \mathrm{~ms}$ duration were applied. Topical $0.1 \%$ dexamethasone drops were used postoperatively.

One week postoperatively the IOP was well controlled $(16 \mathrm{~mm} \mathrm{Hg})$, however, the visual acuity had deteriorated significantly to $1 / 60$ with only temporal visual field remaining. There was no associated anterior chamber shallowing. Dilated fundoscopy revealed widespread exudative retinal detachment with shifting fluid, suggestive of uveal effusion syndrome (UES). (Figure 1a). Examination of the contralateral (right) fundus revealed a small annular cilio-choroidal detachment in the far periphery (Figure 1b).

Initial management consisted of upright posturing and a 6 week reducing dose of oral Prednisolone $1 \mathrm{mg} / \mathrm{kg}$.

Table 1 Nanophthalmic biometry with characteristic hypermetropia, short axial length and thickened sclerae

\begin{tabular}{lcc}
\hline & Right eye & Left eye \\
\hline Corrected visual acuity & $6 / 24$ & $6 / 24$ \\
Refraction, D & +14.00 & +14.00 \\
Axial length, mm & 15.64 & 15.86 \\
Posterior scleral thickness, mm & 2.2 & 2.0 \\
\hline
\end{tabular}
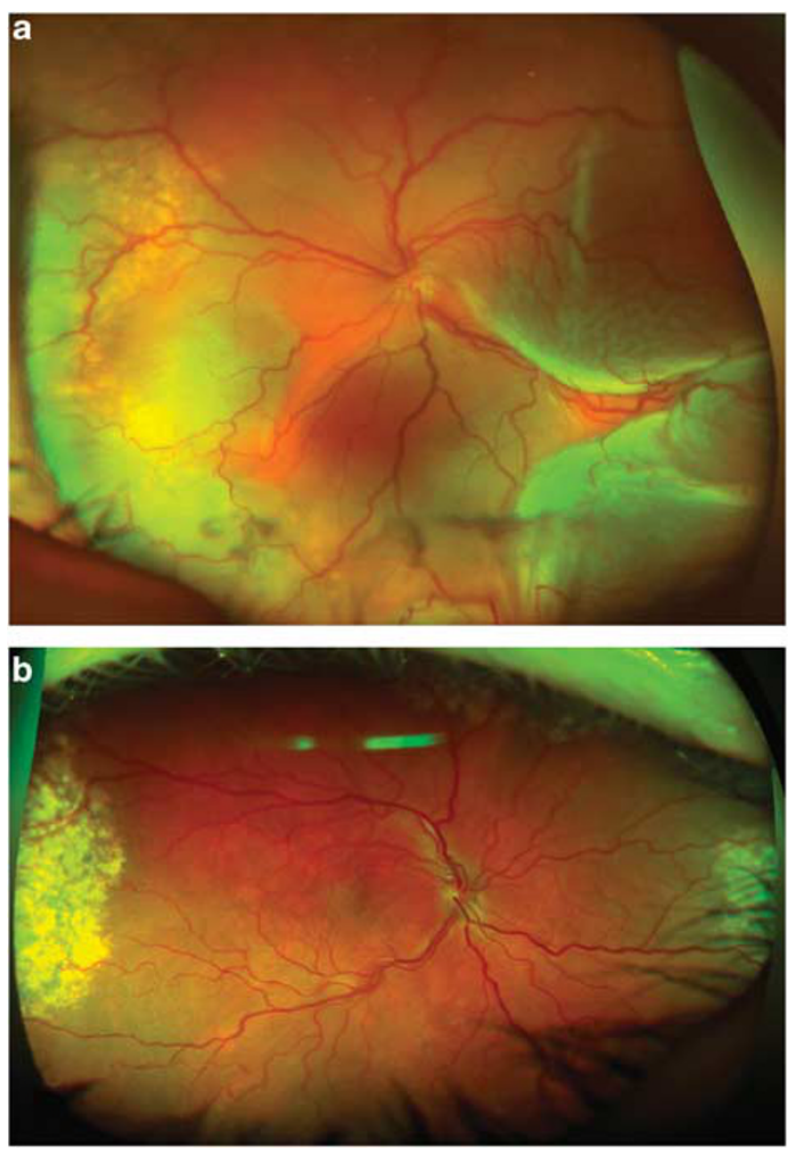

Figure 1 (a) Optomap image of uveal effusion syndrome in the left eye following cyclodiode laser, with extensive serous retinal detachment and shifting subretinal fluid affecting the macula. (b) Optomap image of the right (contralateral) eye demonstrating nasal and temporal exudation as a result of annular ciliochoroidal detachment in the periphery.

Two weeks thereafter, the macula had reattached and the visual acuity had returned to baseline $(6 / 24)$, with IOP controlled at $15 \mathrm{~mm} \mathrm{Hg}$. Complete re-attachment was confirmed by 3 months, and her visual acuity, intraocular pressure and fields remain stable at 1 year.

\section{Comment}

Idiopathic UES is the topic of a current British

Ophthalmic Surveillance Unit (BOSU) study and primary scleral abnormality has been identified as the underlying cause. ${ }^{2}$ Abnormal deposition of glycosaminoglycans result in scleral thickening and impeded trans-scleral flow of fluid and protein. ${ }^{3}$

Cyclodiode appears at first an attractive option to reduce intraocular pressure in this condition. However, in this case, resultant inflammation and increased extravasation of protein compromised an already tenuous diffusion of protein and fluid across the abnormal sclera. It has been postulated that protein accumulation in the choroid with elevated colloid osmotic pressure causes fluid to accumulate, subsequently choroidal detachment, retinal pigment epithelium (RPE) decompensation and extensive serous 